\title{
Repair Bond Strength of Composite Resin to Aged Resin and Glass-Matrix CAD/CAM Ceramic Materials Using Two Different Repair Systems
}

\author{
Sarah Alnafaiy ${ }^{1, *}$, Nawaf Labban ${ }^{1}$, Ahmed Maawadh ${ }^{2}$, Huda Alshehri ${ }^{1}$ (D) and Refal Albaijan ${ }^{3}$ \\ 1 Department of Prosthetic Dental Sciences, College of Dentistry, King Saud University, P.O. Box 60169, \\ Riyadh 11545, Saudi Arabia; nalabban@ksu.edu.sa (N.L.); hAlShehri@ksu.edu.sa (H.A.) \\ 2 Department of Restorative Dental Sciences, College of Dentistry, King Saud University, P.O. Box 60169 \\ Riyadh 11545, Saudi Arabia; amaawadh@ksu.edu.sa \\ 3 Department of Prosthetic Dental Sciences, College of Dentistry, Prince Sattam Bin Abdul Aziz University, \\ Alkharj 11942, Saudi Arabia; r.albaijan@psau.edu.sa \\ * Correspondence: 438203602@student.ksu.edu.sa
}

\section{check for} updates

Citation: Alnafaiy, S.; Labban, N.; Maawadh, A.; Alshehri, H.; Albaijan, R. Repair Bond Strength of Composite Resin to Aged Resin and Glass-Matrix CAD/CAM Ceramic Materials Using Two Different Repair Systems. Coatings 2021, 11, 1331. https://doi.org/10.3390/ coatings11111331

Academic Editor: Csaba Balázsi

Received: 1 October 2021

Accepted: 28 October 2021

Published: 29 October 2021

Corrected: 22 April 2022

Publisher's Note: MDPI stays neutral with regard to jurisdictional claims in published maps and institutional affiliations.

Copyright: (c) 2021 by the authors. Licensee MDPI, Basel, Switzerland. This article is an open access article distributed under the terms and conditions of the Creative Commons Attribution (CC BY) license (https:/ / creativecommons.org/licenses/by/ $4.0 /)$.

\begin{abstract}
This study evaluates the repair bond strength of resin-matrix and glass-matrix CAD/CAM ceramic materials based on two repair systems. Thirty specimens measuring $2.5 \mathrm{~mm}$ in thickness were prepared from Crystal Ultra (CU), Vita Enamic (EN), Lava Ultimate (LU), Cerasmart (CS), and Vitablocs Mark II (VM2) materials and aged for 5000 thermal cycles. Specimens were randomly allocated into three groups: control, Monobond-S (MS) primer, and Monobond Etch \& Prime (MEP). Composite resin (Tetric N Ceram) (5 mm in diameter and $2 \mathrm{~mm}$ thick) was packed and lightcured onto treated specimen surfaces. Subsequently, the specimens' shear bond strength (SBS) was evaluated, and failure modes was recorded. Statistical analysis was performed using factorial ANOVA and Tukey's post hoc tests $(\mathrm{a}=0.05)$. The factorial ANOVA revealed significant interactions between the material type and repair system, which was significant $(p<0.01)$. The highest and lowest SBS were obtained for CU $(27.09 \pm 1.11)$ and VM2 $(4.30 \pm 0.59)$ in MS and control groups, respectively. In all the groups, CU demonstrated higher SBS, whereas VM2 demonstrated lower SBS. There were no significant differences in SBS between EN and LU, and CS and CU in all the study groups $(p>0.05)$. The Monobond-S repair system provided non-significantly higher SBS compared to the MEP systems, except for VM2 and LU materials. The new resin-matrix CAD/CAM material demonstrated the highest SBS compared to the other materials for both conventional and MEP repair systems. Both repair systems showed clinically acceptable bond strength and allowed for successful repair of the resin-matrix ceramic materials.
\end{abstract}

Keywords: bond strength; CAD/CAM materials; resin composites; resin-matric ceramics; thermal-cycling

\section{Introduction}

Dental ceramic materials are classified into glass-matrix ceramics, polycrystalline ceramics, and resin-matrix ceramics [1]. Resin-matrix ceramic materials were developed to combine the advantageous properties of composite resin and ceramic materials. Accordingly, the strength, color stability, and durability of ceramics were combined with ease of machinability, low abrasiveness, polishability, and intra-oral repairability properties of composite resin [2]. Another advantage of these materials is the low modulus of elasticity compared to pure ceramic materials, providing good resilience, thereby improving the resistance to damaging occlusal forces. The polymer component of these materials has improved the biomechanical properties of ceramic material, making it highly indicated to be used in implant-supported fixed prosthesis cases as it reduces the transmitted stresses to the peri-implant structures [3-6]. 
Many resin-matrix ceramic materials are available with different compositions, manufacturing techniques, and ceramic/polymer ratios [7]. These materials are available in blocks and discs to expand their use in dental practice, notably implant dentistry, due to their high polymer content. VITA ENAMIC ${ }^{\circledR}$ (VITA Zahnfabrik) is comprised of a dual interpenetrating network of aluminum oxide-enriched feldspar ceramic (86 wt.\%) and a polymer, which contains urethane dimethacrylate (UDMA) and triethyleneglycol dimethacrylate (TEGDMA) (14 wt.\%) [8,9]. The other types of clinically established resin-matrix ceramics are Lava ${ }^{\mathrm{TM}}$ Ultimate (3M ESPE) and CERASMART ${ }^{\mathrm{TM}}$ (GC America) $[6,10,11]$. Lava ${ }^{\mathrm{TM}}$ Ultimate, a resin-based block nanocomposite consists of nanosized ceramic filler particles ( $80 \%$ by weight) enclosed in a highly cured resin matrix [12]. In contrast, CERASMART is a silica and barium glass nanoparticles-filled (71\% by weight) high-density composite resin [11].

However, any ceramic-based restoration is susceptible to fracture under clinical applications, making it pertinent to evaluate the reparability of these resin-matrix ceramic materials [13]. It was claimed that resin-matrix ceramic materials create a strong chemical bond with resin materials due to the high polymer component. This strong adhesion will facilitate the reparability of dental prostheses if they chip or fracture, particularly in cases of full-arch implant-supported prostheses. Dental manufacturers are trying to revolutionize and simplify the reparability of restorations instead of replacing them [13]. Intra-oral repair is an alternative to extra-oral repair or complete restoration replacement, minimizing cost and resources, reducing the treatment time, and preserving the tooth structure [14,15].

Different ceramic repair systems have been developed involving mechanical and chemical adhesion protocols. This includes acid etching (hydrofluoric acid, HF, phosphoric acid, $\mathrm{H}_{3} \mathrm{PO}_{4}$, and acidulated phosphate fluoride, APF), airborne particle abrasion, and silanization [16]. However, there is no evidence on which repair procedure is the most effective in terms of ensuring a favorable clinical outcome. Several factors influence the bond strength of resin composites to dental ceramics during repairs, such as ceramic type, repair process, aging condition, and resin composite type [17].

The use of airborne-particle abrasion and hydrofluoric acid etching has demonstrated an enhanced adhesion strength compared to other methods. The roughness created by these methods increases the total surface area of the ceramic surfaces and subsequently increases the micromechanical retention with the resin composite. Conversely, HF has hazardous potential, and its intra-oral use cannot be recommended [18,19]. Therefore, this has led to the development of a new, safe one-bottle self-etching primer, Monobond Etch \& Prime (MEP) (Ivoclar Vivadent), which is also found to reduce the time and steps compared to the conventional technique [20]. The MEP primer contains ammonium polyfluoride etchant and trimethoxypropyl methacrylate silane in one bottle. Ammonium polyfluoride has shown to have less acidity than HF, leading to a more negligible acid effect and roughness on the surfaces of the ceramic materials $[20,21]$.

Crystal Ultra (CU; Digital Dental) is a new resin-matrix ceramic material with a high polymer/ceramic ratio and comprises 70\% ceramic-like inorganic silicate glass fillers with $30 \%$ cross-linked polymers $[2,22,23]$. The material's composition differs significantly from that of well-known resin-matrix ceramics. As a result, the adhesion strength of a resin composite to this new material is of particular relevance due to the greater polymer content.

To the best of the authors' knowledge, limited evidence exists regarding the repair bond strength of the resin composite to the new resin-matrix CAD/CAM ceramic material. Consequently, the purpose of this study was to assess the repair bond strength of a new resin-matrix CAD/CAM ceramic material (Crystal Ultra) in comparison to the other wellknown resin-matrix and glass-matrix CAD/CAM ceramic materials, based on two repair systems. The first null hypothesis was that there is no significant difference in repair bond strength between study materials. The second null hypothesis is no significant difference in repair bond strength between the two repair systems. 


\section{Materials and Methods}

The shear bond strength (SBS) of five CAD/CAM restorative materials with two ceramic repair systems was evaluated in the present study. The details of the materials used are shown in Table 1.

Table 1. Materials evaluated in the study.

\begin{tabular}{|c|c|c|}
\hline Material & Manufacturer & Composition \\
\hline \multicolumn{3}{|r|}{ CAD/CAM Ceramics } \\
\hline $\begin{array}{l}\text { Vitablocs Mark II } \\
\qquad \text { (VM2) }\end{array}$ & $\begin{array}{c}\text { Vita Zahnfabrik, H. } \\
\text { Rauter GmbH \& Co, Bad } \\
\text { Säckingen, Germany }\end{array}$ & Feldspathic ceramic $\left(56-64 \% \mathrm{SiO}_{2}, 20-23 \%, \mathrm{Al}_{2} \mathrm{O}_{3}, 6-9 \% \mathrm{Na}_{2} \mathrm{O}, 6-8 \% \mathrm{~K}_{2} \mathrm{O}\right.$ ) \\
\hline $\begin{array}{l}\text { Vita Enamic } \\
\qquad(\mathrm{EN})\end{array}$ & $\begin{array}{l}\text { Vita Zahnfabrik, H. } \\
\text { Rauter GmbH \& Co, Bad } \\
\text { Säckingen, Germany }\end{array}$ & $\begin{array}{c}\text { Cross-linked polymer (BisGMA, UDMA) }(14 \text { wt.\%) and feldspathic ceramic } \\
\text { enriched with } \mathrm{Al}_{2} \mathrm{O}_{3}(86 \text { wt. } \%)\end{array}$ \\
\hline $\begin{array}{l}\text { Lava Ultimate } \\
\text { Restorative } \\
\text { (LU) }\end{array}$ & $\begin{array}{l}\text { 3M ESPE St. Paul, } \\
\text { MN, USA }\end{array}$ & $\begin{array}{l}\text { Matrix: BisGMA, UDMA, BisEMA, TEGDMA } \\
\text { Filler: silica, zirconia nanoparticles and zirconia/silica nanoclusters (80 wt.\%) }\end{array}$ \\
\hline $\begin{array}{l}\text { Cerasmart } \\
\text { (CS) }\end{array}$ & $\begin{array}{l}\text { GC America, Alsip, } \\
\text { IL, USA }\end{array}$ & $\begin{array}{c}\text { Matrix: BisMEPP, UDMA, DMA Filler: silica and barium glass } \\
\text { nanoparticles (71 wt. } \%)\end{array}$ \\
\hline $\begin{array}{l}\text { Crystal Ultra } \\
\quad(\mathrm{CU})\end{array}$ & $\begin{array}{l}\text { Digital Dental, } \\
\text { Scottsdale, AZ, USA }\end{array}$ & $\begin{array}{c}\text { Cross-linked polymer (BisGMA, UDMA, BUDMA) }(30 \mathrm{wt} . \%) \text { and ceramic-like } \\
\text { inorganic silicate glass fillers (70 wt. } \%)\end{array}$ \\
\hline \multicolumn{3}{|r|}{ Repair Systems } \\
\hline $\begin{array}{l}\text { Monobond-S } \\
\quad(\mathrm{MS})\end{array}$ & $\begin{array}{l}\text { Ivoclar Vivadent AG, } \\
\text { Schaan, Liechtenstien }\end{array}$ & $\begin{array}{l}\text { Ethanol,3-trimethoxysilylpropyl methacrylate, methacrylated phosphoric acid } \\
\text { ester, disulfide acrylate }\end{array}$ \\
\hline $\begin{array}{l}\text { Monobond Etch } \\
\text { \& Prime } \\
(\mathrm{MEP})\end{array}$ & $\begin{array}{l}\text { Ivoclar Vivadent AG, } \\
\text { Schaan, Liechtenstien }\end{array}$ & $\begin{array}{l}\text { Buthanol, tetrabutylammonium dihydrogen trifluoride, methacrylated phosphoric } \\
\text { acid ester, bis(triethoxysilyl)ethane }\end{array}$ \\
\hline Heliobond & $\begin{array}{l}\text { Ivoclar Vivadent AG, } \\
\text { Schaan, Liechtenstien }\end{array}$ & Bis-GMA and TEGDMA (99 wt. \%), catalysts and stabilizers $<1 \%$ \\
\hline Tetric N Ceram & $\begin{array}{l}\text { Ivoclar Vivadent AG, } \\
\text { Schaan, Liechtenstien }\end{array}$ & $\begin{array}{l}\text { DMA (17-18 wt. \%), filler load } \\
82-83 \text { wt. } \% \text {, catalysts, stabilizers and pigments (<1.0 wt. \%) }\end{array}$ \\
\hline
\end{tabular}

BisGMA-bisphenol-A-glycidyldimethacrylate; UDMA-Urethane Dimethacrylate; BisEMA-Ethoxylated bisphenol A dimethacrylate; TEGDMA - triethyleneglycoldimethacrylate; BisMEPP-Bisphenol A bis (2-hydroxyethyl ether) dimethacrylate; and DMADimethacrylate; BUDMA-1, 4-butanediol dimethacrylate.

Thirty specimens measuring $2.5 \pm 0.05 \mathrm{~mm}$ in thickness were prepared from five CAD/CAM restorative materials. The sample size calculation was in accordance with previous studies which required a minimum of eight samples to demonstrate the significance [24,25]. The specimens were sectioned from $14 \mathrm{~mm} \times 12 \mathrm{~mm} \times 18 \mathrm{~mm}$ CAD/CAM blocks for CS, EN, LU, and VM2, and $15 \mathrm{~mm} \times 15 \mathrm{~mm} \times 38.8 \mathrm{~mm}$ CAD/CAM blocks for CU using water-cooled low-speed automated precision saw (IsoMet 1000, Buehler, Bluff, IL, USA). The specimen thickness was confirmed using a digital micrometer (Digimatic Micrometer; Mitutoyo, Japan) and was individually embedded in self-cured acrylic resin (Takilon, Rodont, Italy). The specimen surface was standardized by wet-grinding in a polishing machine (LaboPol-25; Struers, Cleveland, OH, USA) under water-coolant at $300 \mathrm{rpm}$, utilizing different grits of silicon carbide paper; 400, 600, 800, 1000, and 1200 grit (Water Proof SiC Paper; Struers, Cleveland, OH, USA) for $30 \mathrm{~s}$. Specimens were cleaned for $10 \mathrm{~min}$ in an ultrasonic bath (Quantrex 90 WT, L\&R Manufacturing, Inc., Kearny, NJ, USA) containing distilled water and air-dried for $40 \mathrm{~s}$. The specimens were then subjected to aging in a thermo-cycling unit (CS-4.2, THE-1100, SD-Mechatronik, Feldkirchen-Westerham, Germany). A total of 5000 thermal-cycles between 5 and $55^{\circ} \mathrm{C}$, with a dwell time of $30 \mathrm{~s}$ and a transfer time of $15 \mathrm{~s}$, was applied [2].

Following aging, specimens from each material were randomly allocated into three groups $(\mathrm{n}=10)$. Group 1 -control or no surface treatment. Group $2(\mathrm{MS})-$ the specimen was surface treated according to the manufacturer's recommendations. VM2, EN, and 
CS specimens were treated with HF acid (5\% Ultradent Porcelain Etch; Ultradent Product Inc., Jordan, UT, USA) for $60 \mathrm{~s}$, rinsed with water, and air-dried for another $60 \mathrm{~s}$. LU and CU specimens were airborne-particle abraded (LEMAT NT4, Wassermann, Hamburg, Germany) for $10 \mathrm{~s}$ with 50- $\mu \mathrm{m}$ aluminum oxide (Korox 50; Bego, Bremen, Germany) at 2 bar pressure and a distance of $10 \mathrm{~mm}$ from the nozzle tip to the specimen surface. Specimens were cleaned ultrasonically in alcohol for $15 \mathrm{~min}$, then dried with oil-free air. Following surface treatment, MS was applied with a brush, allowed to react for $60 \mathrm{~s}$, and excess solution was dislodged with a strong oil-free air stream to ensure solvent evaporation. Group 3 (MEP) - the single bottle etch, and primer solution was applied onto the specimen surfaces using a brush for $20 \mathrm{~s}$, allowed to react for $60 \mathrm{~s}$, and rinsed thoroughly. The specimen treatment and distribution is presented as a flow chart in Figure 1.

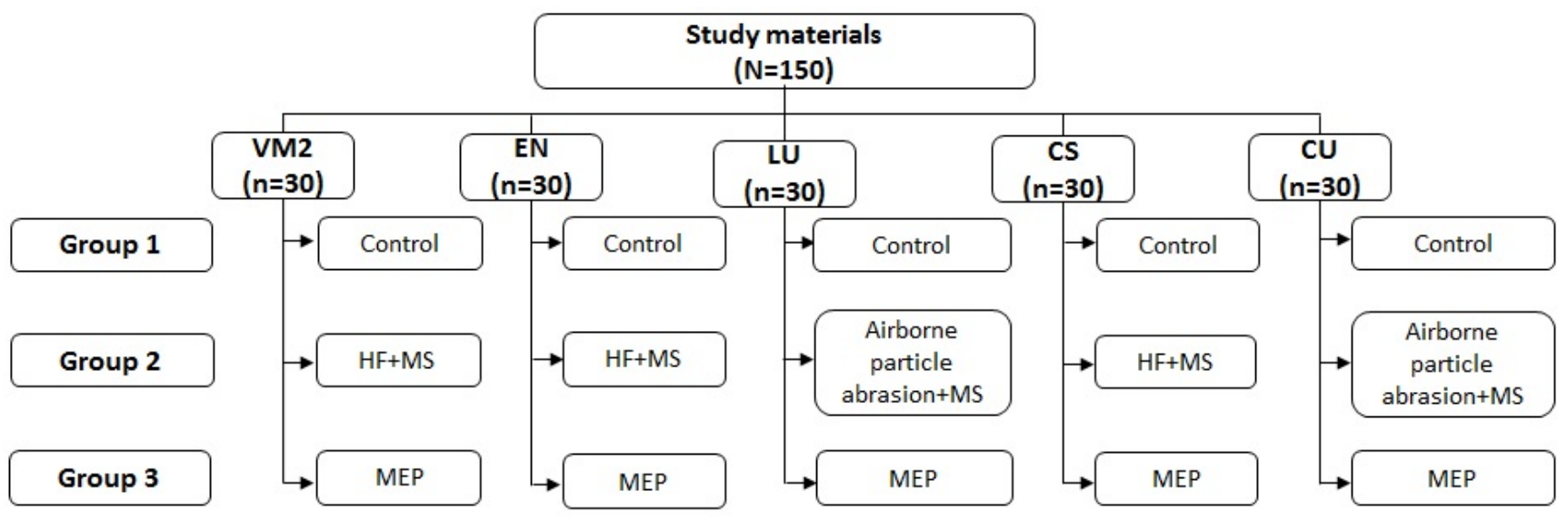

Figure 1. Schematic presentation of the study process and specimen distribution.

Adhesive agent (Heliobond, Ivoclar Vivadent AG, Schaan, Liechtenstein) was applied to all the specimens using a micro-brush, and air-dried to obtain a thin layer, then light-polymerized using a light-curing unit (Bluephase ${ }^{\circledR}$, Ivoclar Vivadent AG, Schaan, Liechtenstien; light output, $650 \mathrm{~mW} / \mathrm{cm}^{2}$ ) for $10 \mathrm{~s}$. For simulation of the repair procedure, silicon molds with $5 \mathrm{~mm}$ diameter and $2 \mathrm{~mm}$ thickness were positioned at the center of the prepared specimen. Next, resin composite (Tetric N Ceram) was packed into the mold and light-polymerized (Bluephase ${ }^{\circledR}$, Ivoclar Vivadent AG, Schaan, Liechtenstien; light output, $1200 \mathrm{~mW} / \mathrm{cm}^{2}$ ) for $10 \mathrm{~s}$ (Figure 2a). The silicone mold was gently sectioned using a scalpel, and excess composite material was removed. The specimens were then stored in distilled water at room temperature for $24 \mathrm{~h}$ before the SBS test.

The specimens were placed in a custom-made holder of a universal testing machine (Model \# 5969; Instron Corp, Norwood, MA, USA) for SBS testing. A shear force was applied to the adhesive interface between the ceramic specimen and the composite resin through a knife-edge shaped loading device at a $1 \mathrm{~mm} / \mathrm{min}$ crosshead speed until failure (Figure $2 b$ ). The load at debonding was recorded, and the SBS values were calculated from the below Equation (1) [25]:

$$
\mathrm{SBS}=\mathrm{F} / \mathrm{d}
$$

where $\mathrm{F}$ is the force $(\mathrm{N})$ and $\mathrm{d}$ is the bonding surface area $\left(\mathrm{mm}^{2}\right)$.

The de-bonded site was examined for failure mode with a stereomicroscope (Nikon model SMZ 1500; Nikon Instech Co, Ltd., Kanagawa, Japan) at 15× magnification. The failure mode was categorized as adhesive interface failure, cohesive failure in the ceramic material, cohesive failure in the resin composite, or mixed failure involving adhesive material interface.

Before bonding, a representative specimen from each group was selected for surface topography assessment using a scanning electron microscope (SEM) (Quanta 250FEG; FEI Co., Tokyo, Japan). Specimens were air-dried, and the imaging surface was sputter-coated 
with gold-palladium. SEM micrographs of the specimens were obtained at a voltage of $20 \mathrm{kV}$, in a vacuum, and with a $2000 \times$ magnification.

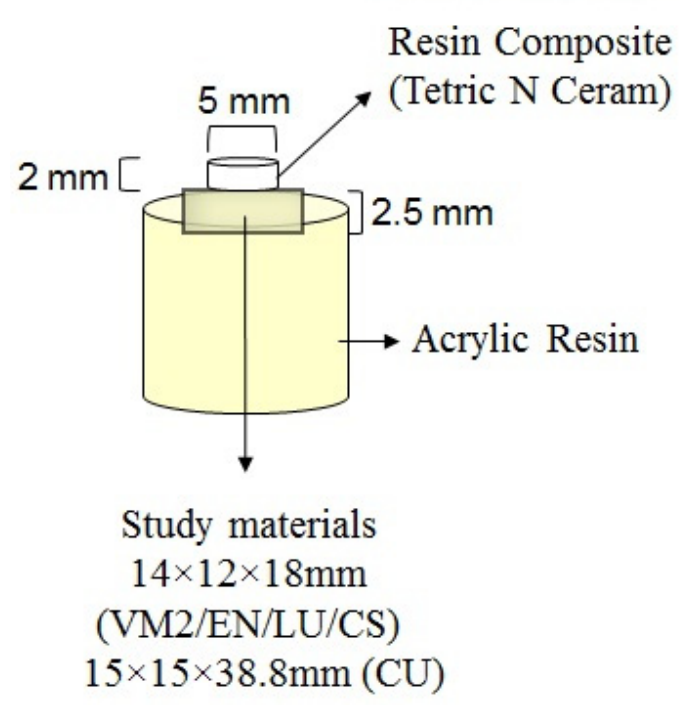

a

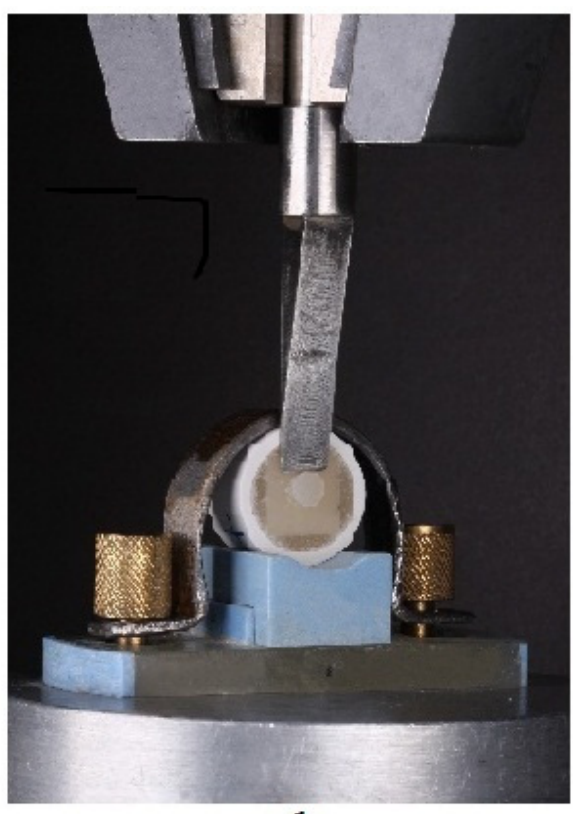

b

Figure 2. Specimen dimension (a), and shear bond strength (SBS) test set-up (b).

All data analysis was performed using 20 SPSS statistical software (IBM SPSS Inc., Armonk, NY, USA). The normality of data distribution was tested by Kolmogorov-Smirnov test, which showed normal distribution for all the groups. Factorial ANOVA was applied to evaluate the effect of the material, repair system type, and the interaction between them on the SBS. Tukey's post hoc test was used to detect the significant differences between the groups $(\alpha=0.05)$.

\section{Results}

Factorial ANOVA revealed significant interactions between the material type $(\mathrm{F}=55.24$; $p<0.001)$ and repair system $(\mathrm{F}=679.44 ; p<0.001)$, and the interactions between them were significant $(\mathrm{F}=10.07 ; p<0.001)$ (Table A1).

Table 2 presents the mean SBS and SD of the aged resin-matrix CAD/CAM materials following resin composite repair. The highest and lowest SBS were obtained for CU $(27.09 \pm 1.11)$ and VM2 $(4.30 \pm 0.59)$ in MS and control groups, respectively. In all the groups, CU demonstrated higher SBS, whereas VM2 demonstrated lower SBS. There were no significant differences in SBS between EN and LU, and CS and CU in all the study groups $(p>0.05)$. Monobond-S repair system provided non-significantly higher SBS compared to MEP systems, except for VM2 and LU materials. In contrast, significantly higher SBS was obtained for the Monobond-S repair system compared to the control group.

Figure 3 displays the percentage failure mode distribution of the specimen groups. The control group specimens in all the materials showed adhesive failures $(100 \%)$. In the MS group, EN and LU specimens all showed cohesive failure, whereas, for the remaining materials (VM2, CS, and CU), the cohesive failure was above $50 \%$ and adhesive failures within the 20 to $40 \%$ range. In the MEP group, the predominant failure was cohesive, followed by mixed failures. No adhesive failures were observed in this group for any of the tested materials. 
Table 2. Mean shear bond strength values (MPa) of the tested materials.

\begin{tabular}{cccc}
\hline \multirow{2}{*}{ Materials } & \multicolumn{3}{c}{ Groups } \\
\cline { 2 - 4 } & Control & MS & MEP \\
\hline VM2 & $4.30 \pm 0.59^{\mathrm{A}, \mathrm{a}}$ & $19.18 \pm 3.71^{\mathrm{B}, \mathrm{a}}$ & $12.80 \pm 0.67^{\mathrm{C}, \mathrm{a}}$ \\
EN & $4.97 \pm 1.14^{\mathrm{A}, \mathrm{a}, \mathrm{b}}$ & $20.52 \pm 1.39^{\mathrm{B}, \mathrm{a}}$ & $17 \pm 1.15^{\mathrm{B}, \mathrm{b}}$ \\
LU & $6.52 \pm 1.12^{\mathrm{A}, \mathrm{b}}$ & $20.59 \pm 2.41^{\mathrm{B}, \mathrm{a}}$ & $15.83^{\mathrm{B}} \pm 3^{\mathrm{C}, \mathrm{a}, \mathrm{b}}$ \\
CS & $4.36 \pm 1.31^{\mathrm{A}, \mathrm{a},}$ & $25.67 \pm 1.58^{\mathrm{B}, \mathrm{b}}$ & $23.86 \pm 2.05^{\mathrm{B}, \mathrm{c}}$ \\
CU & $8.14 \pm 3.96^{\mathrm{A}, \mathrm{b}}$ & $27.09 \pm 1.11^{\mathrm{B}, \mathrm{b}}$ & $24.50 \pm 3.06^{\mathrm{B}, \mathrm{c}}$ \\
\hline
\end{tabular}

Same upper case superscript letters within a row indicates mean values with no statistically significant difference $(p>0.05)$. Same lower case superscript letters within a column indicates mean values with no statistically significant difference $(p>0.05)$. Vitablocs Mark II, VM2; Vita Enamic, EN; Lava Ultimate, LU; Cerasmart, CS; and Crystal Ultra, CU.

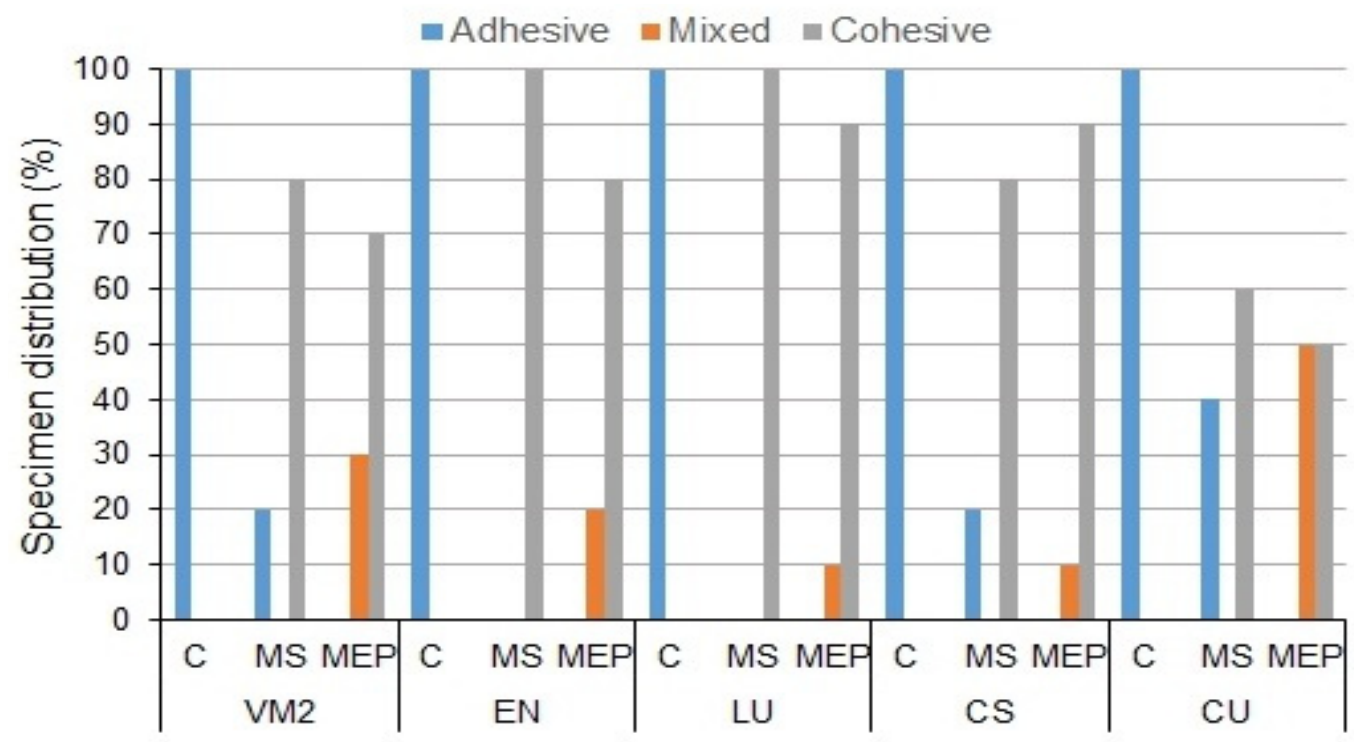

\section{Study materials and groups}

Figure 3. Failure mode analysis of the materials.

SEM micrographs of the representative specimen from the study materials before resin composite bonding are presented in Figure 4. There were no evident changes in the specimens of the control groups for all the materials. In the MS group, LU showed severe surface changes in the form of pores and irregularities, followed by moderate surface changes of VM2, EN, and CU, and mild changes in CS. In group MEP, VM2 and EN showed severe surface changes, and other materials showed moderate surface irregularities. 

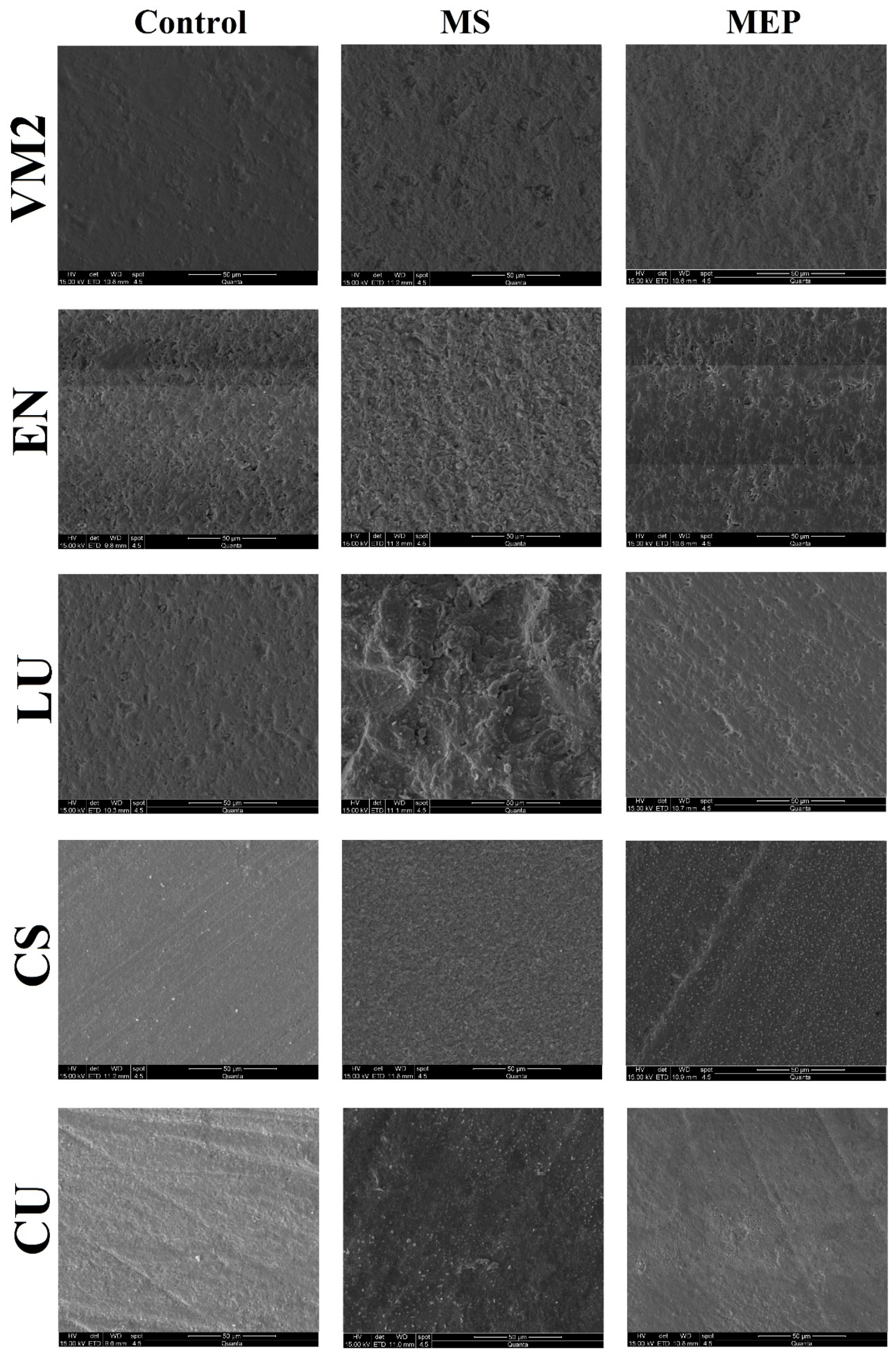

Figure 4. Scanning electron microscopy (SEM) micrographs of the study materials following surface treatment. 


\section{Discussion}

This study evaluated the SBS of four aged resin-matrix ceramic materials and one feldspathic material with two different intra-oral repair systems. There were no significant differences in SBS between EN and LU, and CS and CU in all the study groups. Furthermore, the Monobond-S repair system provided non-significantly higher SBS than MEP systems except for VM2 and LU materials. Based on these results, the null hypotheses of the study that there is no significant difference in repair bond strength between study materials and two repair systems, were partially accepted.

Ceramic fracture has shown to be one of the significant complications of ceramic restorations, which requires either complete replacement or repair [26]. However, intra-oral repair of chipped or fracture ceramic restoration has shown to be an alternative to the total replacement or extra-oral repair, offering the patient and dentist a cost-effective treatment, reducing the number of treatment steps, and preservation of the tooth structure $[14,15]$.

In this study, the repair bond strength of the study materials was tested using a shear bond test, one of the most commonly used tests due to its reliability and ease of use [25]. In vitro simulations can assist in estimating the longevity of dental materials by assessing their mechanical and structural degradation characteristics as they age in the clinical environment. Although laboratory testing and in vitro research cannot completely replicate intra-oral conditions such as the clinical environment, moisture, and forces inflicted on teeth and restorations, they can, to some extent, simulate them [27]. Thermal cycling is one of the most extensively applied aging techniques in laboratory research. It is also well accepted in international literature among the currently available methods capable of replicating dynamic stresses [28]. However, there is no strict thermal cycling protocol applied in previous studies. In the current study, all the specimens were subjected to 5000 thermal cycles to simulate intra-oral aging, corresponding to six months of clinical service [29]. Resin-matrix ceramic materials, when exposed to repeated thermal changes, undergo expansion and contraction, leading to mechanical stresses and crack formation, thus affecting the properties of the tested materials $[28,30]$.

Ceramic repair systems have different mechanical and chemical adhesion protocols such as HF etching, airborne-particle abrasion, and silanization. Airborne-particle abrasion and HF etching have been shown to increase the ceramic materials' surface area, thus increasing the micromechanical retention with the resin composite. Airborne-particle abrasion increases the total surface area by making minor obtuse-angular roughness on the ceramic surface, reducing the surface tension and enhancing the resin wettability [31]. On the other hand, HF dissolves the glass matrix, creating micro-porosity on the ceramic surface [32]. Silanization by silane-containing primer after HF etching or airborne-particle abrasion is advocated to enhance the chemical adhesion. Silane is a monomer that contains a silanol group that chemically bonds to the ceramic $\mathrm{SiO}_{2}$ and methacrylate groups of the resin composite leading to strong adhesion $[16,33]$.

It is essential to mention that HF is highly toxic and burns the contact tissue, requiring utmost precautions. In overcoming such a hazardous situation, MEP self-etching primers are used $[18,19]$. This primer contains ammonium polyfluoride, a safer acid salt etchant than HF, and trimethoxypropyl methacrylate silane in one bottle. Furthermore, they reduce treatment time by eliminating the etching process [20]. In this study, the MEP primer was compared with conventional Monobond-S primer and a control group with no surface treatment. The study results revealed that both types of repair systems increased the SBS of each material compared to the control groups. Monobond-S repair system provided non-significantly higher SBS compared to MEP systems, except for VM2 and LU materials. In contrast, significantly higher SBS was obtained for the Monobond-S repair system compared to the control group. The international standard organization (ISO)-10477:2020 defines a bond strength of $5 \mathrm{MPa}$ to the material [34], however, other investigations have identified $10 \mathrm{MPa}$ as the critical SBS value, and values higher than $10 \mathrm{MPa}$ are considered acceptable [35]. In this regard, the SBS values of the specimens in Monobond-S and MEP groups were well above the critical value $(10 \mathrm{MPa})$. For clinical applications, it was also 
reported that the optimal bond strength for direct resin composite and hybrid ceramic materials ranges between 15 and $25 \mathrm{Mpa}[36,37]$. Still, the SBS of control specimens with no surface treatment was below this limit.

In the Monobond-S primer groups, surface preparation following the manufacturer's instructions for each material was performed; EN, CS, and VM2 were treated with HF whereas LU and CU were airborne-particle abraded, then silane-containing primer was applied (Monobond-S primer) followed by an adhesive agent, and composite resin. The second repair system uses the self-etching primer, followed by an adhesive agent and resin composite. $\mathrm{CU}$ is one of the newly developed resin-matrix ceramic materials. It has the highest polymer/ceramic ratio compared to the other resin-matrix ceramic materials [2]. $\mathrm{CU}$ has a high adhesion affinity to silane as it is composed of 70\% ceramic particles based on $\mathrm{SiO}_{2}$, and $30 \%$ highly cross-linked polymer blends [2,22]. CU and CS had the highest SBS values in both repair systems, and this could be related to their high contents of $\mathrm{SiO}_{2}$, and polymer/ceramic ratios, which are $30 \%$ and $29 \%$, respectively, compared to the other materials [16,33].

Contrarily, one study showed no significant difference between CS and LU when treated with HF acid, followed by silane-containing primer application, adhesive agent, and resin composite [24]. However, the comparison with previous studies should be considered cautiously due to the different repair systems, surface treatment, and testing methods. EN, LU, and VM2 had comparable SBS values in the groups of Monobond-S primer. However, EN had higher SBS values than VM2 when the materials were treated with MEP, and this is due to the low acid effect on the glass-matrix material, particularly with the week etchant of the MEP [33]. These findings are consistent with previous studies demonstrating similar outcomes [20,25]. EN and LU have comparable compositions and polymer/ceramic ratios, which could justify their SBS values when treated with both primer systems.

In this study, all MEP groups had lower SBS values than the Monobond-S groups. However, there was no significant difference between the two groups in EN, CS, and CU materials. MEP contains ammonium polyfluoride, an acid salt that showed a more negligible acid effect than HF, which could justify the lower SBS values of the MEP groups [20,21]. Another possible reason would be related to the mix of primer and etchant in one bottle, which reduces the ability to dissolve the glass matrix of the materials [20,38]. Regardless of the acid etch type, the high $\mathrm{SiO}_{2}$ percentages in EN, CS, and CU materials and their high adhesion ability to the silane-containing primer could justify the non-significant $S B S$ values between the two repair systems $[16,33]$. In addition, LU has a higher percentage of zirconia particles than EN and this could justify its lower SBS when treated with MEP only due to the low acid etching effect on the zir-conia [39]. In 2018, El-Damanhoury et al. [20] evaluated the repair bond strength of EN, VM2, and lithium disilicate glass-ceramic to luting resin cement using MEP and conventional HF etching followed by primer and adhesive agent. Their results showed no significant difference between the two repair systems with the resin-matrix ceramic material. This was related to the high contents of silicon dioxide $\left(\mathrm{SiO}_{2}\right)$ and polymers and their high bonding affinity silane-containing primer.

SEM micrographs of the specimens represent the results, showing more irregularities and pores with the use of HF/airborne-particle abrasion followed by the Monobond-S primer than MEP system; these findings are in accordance with a previous study [20]. LU material has the most differentiated ceramic composition; silica, zirconia nanoparticles, and zirconia/silica nanoclusters, and the adhesion between them was reported to be weak compared to purely silicate-based materials [40]. According to the manufacturer's instruction, LU should be airborne-particle abraded before any bonding due to the high effect of abrasion on the zirconia particles compared to acid etching. Due to the previous facts, LU showed more surface changes than other materials in all groups under the SEM. Moreover, high bond strength is attributed to the material composition, chemical and mechanical adhesion between the ceramic material and repair material, rather than the mechanical interlocking to the rough surface [20]. The failure modes of the materials represent the study's results $[20,24,25]$. The five materials showed adhesive failures in 
the control groups, representing low bond strength due to the absence of micro-porosity or surface irregularities. In all the materials, cohesive failures within the ceramics were observed more in the Monobond-S group than MEP group, which infers that the bond strength between the material and composite is higher than the cohesive SBS of the material, and this represents the increased effect of the HF etching/primer compared to the MEP.

The study's primary limitation is that it was unable to simulate the complete intra-oral environment. In intra-oral conditions, diet and oral hygiene procedures play an important role in determining the bond strength of the resin composites to CAD/CAM materials. Furthermore, only the outer surface is exposed to external variables in clinical conditions, while the inner surface is luted to the underlying structure. As a result, expecting that current test results accurately predict clinical reality may be erroneous. Another limitation was using one type of resin composite which could limit the generalizability of the present outcomes. Finally, there was no considerable comparison of the present findings with previous studies due to the inadequate studies concerning repair bond strength of resin composites to resin- and glass-matrix CAD/CAM ceramic materials.

\section{Conclusions}

MEP system and conventional surface treatment techniques showed clinically acceptable repair bond strength with resin-matrix ceramic materials. CU and CS showed significantly higher SBS in both repair systems compared to the other materials. In addition, no significant differences were found between the two systems in each material, except for LU and VM2 materials.

Among the tested materials, the specimens in the MS group demonstrated more of a cohesive failure than the MEP group, hypothesizing the enhanced effect of the HF etching/primer compared to the MEP alone. The use of HF/airborne-particle abrasion followed by the Monobond-S primer showed significant surface changes compared to the application of the MEP system.

Further studies should be conducted to verify the results of this study with in vivo results. Also, future studies should investigate the bond strength of different types of resin composites with MEP. The effect of different beverages and tooth brushing on the bond strength could provide more valuable information regarding the study materials.

Author Contributions: Conceptualization, S.A., N.L. and A.M.; methodology, S.A., H.A., and R.A.; software, N.L. and S.A.; validation, S.A. and A.M.; formal analysis, S.A. and N.L.; investigation, S.A., H.A. and R.A.; re-sources, S.A.; data curation, S.A., N.L. and A.M.; writing-original draft preparation, S.A. and N.L.; writing-review and editing, S.A.; supervision, N.L., A.M. and H.A.; project administration, S.A.; funding acquisition, S.A. and R.A. All authors have read and agreed to the published version of the manuscript.

Funding: The authors would like to thank the Deanship of Scientific Research at King Saud University, Riyadh, Saudi Arabia, for the fund and support during the completion of this study.

Institutional Review Board Statement: Not applicable.

Informed Consent Statement: Not applicable.

Data Availability Statement: Data sharing is not applicable to this article.

Acknowledgments: The authors would like to thank the College of Dentistry Research Centre, King Saud University, Saudi Arabia for the approval and support (Registration No. PR 0107).

Conflicts of Interest: The authors declare no conflict of interest. 


\section{Nomenclature}

$\begin{array}{ll}\text { ANOVA } & \text { Analysis of variance } \\ \text { APF } & \text { Aciduated phosphate fluoride } \\ \text { BisEMA } & \text { Ethoxylated bisphenol A dimethacrylate } \\ \text { BISEMPP } & \text { Bisphenol A bis (2-hydroxyethyl ether) dimethacrylate } \\ \text { BisGMA } & \text { bisphenol-A-glycidyldimethacrylate } \\ \text { BUDMA } & \text { 1,4-butanediol dimethacrylate } \\ \text { CAD/CAM } & \text { Computer-aided design/Computer-aided manufacturing } \\ \mathrm{CS} & \text { Cerasmart } \\ \mathrm{CU} & \text { Crystal Ultra } \\ \mathrm{DMA} & \text { Dimethacrylate } \\ \mathrm{EN} & \text { Vita Enamic } \\ \mathrm{HF} & \text { Hydrofluoric Acid } \\ \mathrm{H}_{3} \mathrm{PO} & \text { phosphoric acid } \\ \mathrm{ISO} & \text { International Organization for Standardization } \\ \mathrm{K}_{2} \mathrm{O} & \text { Potassium oxide } \\ \mathrm{MEP} & \text { Monobond etch and primer } \\ \mathrm{MS} & \text { Monobond-S } \\ \mathrm{MPa} & \text { Megapascal } \\ \mathrm{Na}{ }_{2} \mathrm{O} & \text { Sodium oxide } \\ \mathrm{N} & \text { Newton } \\ \mathrm{SBS} & \text { Shear bond strength } \\ \mathrm{SEM} & \text { Scanning Electron Microscopy } \\ \mathrm{SiO} & \text { Silicon dioxide } \\ \mathrm{SPSS} & \text { Statistical Package for the Social Sciences } \\ \mathrm{TEGDMA} & \text { triethyleneglycoldimethacrylate } \\ \mathrm{UDMA} & \text { Urethane Dimethacrylate } \\ \mathrm{VM} 2 & \text { Vitablocs Mark II }\end{array}$

\section{Appendix A}

Table A1. Results of factorial ANOVA for shear bond strength.

\begin{tabular}{cccccc}
\hline Source & $\begin{array}{c}\text { Type III Sum } \\
\text { of Squares }\end{array}$ & df & $\begin{array}{c}\text { Mean } \\
\text { Square }\end{array}$ & F & $*$ Sig. \\
\hline Corrected Model & 8953.94 & 14 & 639.56 & 118.60 & $<0.001$ \\
Intercept & $37,967.62$ & 1 & $37,967.62$ & 7040.84 & $<0.001$ \\
Material & 1191.53 & 4 & 297.88 & 55.24 & $<0.001$ \\
Repair system & 7327.79 & 2 & 3663.89 & 679.44 & $<0.001$ \\
Material * Repair & 434.60 & 8 & 54.32 & 10.07 & $<0.001$ \\
$\quad$ system & 727.98 & 135 & 5.39 & - & - \\
Error & $47,649.55$ & 150 & - & - & - \\
Total & 9681.92 & 149 & - & - & - \\
Corrected Total & & & & &
\end{tabular}

\section{References}

1. Gracis, S.; Thompson, V.P.; Ferencz, J.L.; Silva, N.R.F.A.; Bonfante, E.A. A new classification system for all-ceramic and ceramic-like restorative materials. Int. J. Prosthodont. 2016, 28, 227-235. [CrossRef]

2. Al Amri, M.D.; Labban, N.; Alhijji, S.; Alamri, H.; Iskandar, M.; Platt, J.A. In vitro evaluation of translucency and color stability of CAD/CAM polymer-infiltrated ceramic materials after accelerated aging. J. Prosthodont. 2020, 30, 318-328. [CrossRef]

3. Awad, D.; Stawarczyk, B.; Liebermann, A.; Ilie, N. Translucency of esthetic dental restorative CAD/CAM materials and composite resins with respect to thickness and surface roughness. J. Prosthet. Dent. 2015, 113, 534-540. [CrossRef] [PubMed]

4. $\quad$ Lauvahutanon, S.; Takahashi, H.; Shiozawa, M.; Iwasaki, N.; Asakawa, Y.; Oki, M.; Finger, W.J.; Arksornnukit, M. Mechanical properties of composite resin blocks for CAD/CAM. Dent. Mater. J. 2014, 33, 705-710. [CrossRef] [PubMed]

5. Lebon, N.; Tapie, L.; Vennat, E.; Mawussi, B. Influence of CAD/CAM tool and material on tool wear and roughness of dental prostheses after milling. J. Prosthet. Dent. 2015, 114, 236-247. [CrossRef] 
6. Ruse, N.; Sadoun, M. Resin-composite blocks for dental CAD/CAM applications. J. Dent. Res. 2014, 93, 1232-1234. [CrossRef] [PubMed]

7. Bajraktarova-Valjakova, E.; Korunoska-Stevkovska, V.; Kapusevska, B.; Gigovski, N.; Bajraktarova-Misevska, C.; Grozdanov, A. Contemporary dental ceramic materials, a review: Chemical composition, physical and mechanical properties, indications for use. Open Access Maced. J. Med. Sci. 2018, 6, 1742-1755. [CrossRef]

8. Della Bona, A.; Corazza, P.H.; Zhang, Y. Characterization of a polymer-infiltrated ceramic-network material. Dent. Mater. 2014, 30, 564-569. [CrossRef]

9. Reich, S. Tooth-colored CAD/CAM monolithic restorations. Int. J. Comput. Dent. 2015, 18, 131-146.

10. Goujat, A.; Abouelleil, H.; Colon, P.; Jeannin, C.; Pradelle, N.; Seux, D.; Grosgogeat, B. Mechanical properties and internal fit of 4 CAD-CAM block materials. J. Prosthet. Dent. 2017, 119, 384-389. [CrossRef]

11. Awada, A.; Nathanson, D. Mechanical properties of resin-ceramic CAD/CAM restorative materials. J. Prosthet. Dent. 2015, 114, 587-593. [CrossRef] [PubMed]

12. Koller, M.; Arnetzl, G.V.; Holly, L. Lava ultimate resin nano ceramic for CAD/ CAM: Customization case study. Int. J. Comput. Dent. 2012, 15, 159-164. [PubMed]

13. Blum, I.R.; Jagger, D.C.; Wilson, N.H.F. Defective dental restorations: To repair or not to repair? part 2: All-ceramics and porcelain fused to metal systems. Dent. Updat. 2011, 38, 150-158. [CrossRef] [PubMed]

14. Kimmich, M.; Stappert, C.F. Intraoral treatment of veneering porcelain chipping of fixed dental restorations: A review and clinical application. J. Am. Dent. Assoc. 2013, 144, 31-44. [CrossRef]

15. Reston, E.G.; Filho, S.C.; Arossi, G.; Cogo, R.B.; Rocha Cdos, S.; Closs, L.Q. Repairing ceramic restorations: Final solution or alternative procedure? Oper. Dent. 2008, 33, 461-466. [CrossRef]

16. Özcan, M.; Vallittu, P.K. Effect of surface conditioning methods on the bond strength of luting cement to ceramics. Dent. Mater. 2003, 19, 725-731. [CrossRef]

17. Elsaka, S.E. Repair bond strength of resin composite to a novel CAD/CAM hybrid ceramic using different repair systems. Dent. Mater. J. 2015, 34, 161-167. [CrossRef] [PubMed]

18. Bertolini, J.C. Hydrofluoric acid: A review of toxicity. J. Emerg. Med. 1992, 10, 163-168. [CrossRef]

19. Özcan, M.; Allahbeickaraghi, A.; Dündar, M. Possible hazardous effects of hydrofluoric acid and recommendations for treatment approach: A review. Clin. Oral Investig. 2011, 16, 15-23. [CrossRef] [PubMed]

20. El-Damanhoury, H.M.; Gaintantzopoulou, M.D. Self-etching ceramic primer versus hydrofluoric acid etching: Etching efficacy and bonding performance. J. Prosthodont. Res. 2018, 62, 75-83. [CrossRef]

21. Della Bona, A.; Shen, C.; Anusavice, K.J. Work of adhesion of resin on treated lithia disilicate-based ceramic. Dent. Mater. 2004, 20, 338-344. [CrossRef]

22. Labban, N.; Al Amri, M.; Alhijji, S.; Alnafaiy, S.; Alfouzan, A.; Iskandar, M.; Feitosa, S. Influence of toothbrush abrasion and surface treatments on the color and translucency of resin infiltrated hybrid ceramics. J. Adv. Prosthodont. 2021, 13, 1-11. [CrossRef]

23. Sarah, A.M.; Nawaf, L.; Ahmed, M.; Huda, A.H.; Abdullah, S.A.; Wejdan, A. Biaxial flexural strength and hardness of resin-matrix ceramic CAD/CAM materials. Ceram.-Silikáty 2021, in press. [CrossRef]

24. Gul, P.; Altınok-Uygun, L. Repair bond strength of resin composite to three aged CAD/CAM blocks using different repair systems. J. Adv. Prosthodont. 2020, 12, 131-139. [CrossRef] [PubMed]

25. Stün, Ö.; Büyükhatipoğlu, I.K.; Seçilmiş, A. Shear bond strength of repair systems to new Cad/Cam restorative materials. J. Prosthodont. 2018, 27, 748-754.

26. Anusavice, K.J. Standardizing failure, success, and survival decisions in clinical studies of ceramic and metal-ceramic fixed dental prostheses. Dent. Mater. 2012, 18, 102-111. [CrossRef]

27. Khoroushi, M.; Shirban, F.; Shirban, M. Marginal microleakage and morphological characteristics of a solvent-free one-step self-etch adhesive (B1SF). J. Dent. 2013, 10, 32-40.

28. Morresi, A.L.; D’Amario, M.; Capogreco, M.; Gatto, R.; Marzo, G.; D’Arcangelo, C.; Monaco, A. Thermal cycling for restorative materials: Does a standardized protocol exist in laboratory testing? A literature review. J. Mech. Behav. Biomed. Mater. 2014, 29, 295-308. [CrossRef] [PubMed]

29. Subaşı, M.G.; Alp, G.; Johnston, W.M.; Yilmaz, B. Effects of fabrication and shading technique on the color and translucency of new-generation translucent zirconia after coffee thermocycling. J. Prosthet. Dent. 2018, 120, 603-608. [CrossRef]

30. Gale, M.; Darvell, B. Thermal cycling procedures for laboratory testing of dental restorations. J. Dent. 1999, 27, 89-99. [CrossRef]

31. Ozcan, M.; Niedermeier, W. Clinical study on the reasons for and location of failures of metal-ceramic restorations and survival of repairs. Int. J. Prosthodont. 2002, 15, 299-302. [PubMed]

32. Szep, S.; Gerhardt, T.; Gockel, H.W.; Ruppel, M.; Metzeltin, D.; Heidemann, D. In vitro dentinal surface reaction of $9.5 \%$ buffered hydrofluoric acid in repair of ceramic restorations: A scanning electron microscopic investigation. J. Prosthet. Dent. 2000, 83, 668-674. [CrossRef]

33. Ozcan, M.; Valandro, L.F.; Amaral, R.; Leite, F.; Bottino, M.A. Bond strength durability of a resin composite on a reinforced ceramic using various repair systems. Dent. Mater. 2009, 25, 1477-1483. [CrossRef] [PubMed]

34. Escobar, M.; Henriques, B.; Fredel, M.C.; Silva, F.S.; Özcan, M.; Souza, J.C. Adhesion of peek to resin-matrix composites used in dentistry: A short review on surface modification and bond strength. J. Adhes. Sci. Technol. 2020, 34, 1241-1252. [CrossRef] 
35. Çulhaoğlu, A.K.; Özkır, S.E.; Şahin, V.; Yılmaz, B.; Kılıçarslan, M.A. Effect of various treatment modalities on surface characteristics and shear bond strengths of polyetheretherketone-based core materials. J. Prosthodont. 2017, 29, 136-141. [CrossRef] [PubMed]

36. Güngör, M.B.; Nemli, S.K.; Bal, B.T.; Ünver, S.; Doğan, A. Effect of surface treatments on shear bond strength of resin composite bonded to CAD/CAM resin-ceramic hybrid materials. J. Adv. Prosthodont. 2016, 8, 259-266. [CrossRef]

37. Wiegand, A.; Stucki, L.; Hoffmann, R.; Attin, T.; Stawarczyk, B. Repairability of CAD/CAM high-density PMMA- and compositebased polymers. Clin. Oral Investig. 2015, 19, 2007-2013. [CrossRef]

38. Siqueira, F.S.; Alessi, R.S.; Cardenas, A.F.; Kose, C.; Bandeca, M.C.; Gomes, J.C. New single-bottle ceramic primer: 6-month case report and laboratory performance. J. Contemp Dent. Pract. 2016, 17, 1033-1039. [CrossRef]

39. Duzyol, M.; Sagsoz, O.; Sagsoz, N.P.; Akgul, N.; Yildiz, M. The effect of surface treatments on the bond strength between CAD/CAM blocks and composite resin. J. Prosthodont. 2015, 25, 466-471. [CrossRef]

40. Thammajaruk, P.; Inokoshi, M.; Chong, S.; Guazzato, M. Bonding of composite cements to zirconia: A systematic review and meta-analysis of in vitro studies. J. Mech. Behav. Biomed. Mater. 2018, 80, 258-268. [CrossRef] 